\title{
A AUTORA COMO XAMÃ OU O QUE DEVE A ARTE DE ANDUJAR AOS YANOMAMI?
}

The author as shaman or what owes the art of Andujar to the Yanomami?

La autora como chamán o ¿qué debe el arte de Andujar a los Yanomami?

João Pedro Garcez ${ }^{1}$

\section{Resumo:}

O texto propõe a fórmula "autora como xamã" para afirmar a presença do xamanismo ameríndio na elaboração da série fotográfica Sonhos (2002-2004) de Claudia Andujar. Para isso, dividimos a argumentação em três momentos. Na primeira parte, recuperamos os textos de Walter Benjamin e Hal Foster sobre a figura do autor - "O autor como produtor" ([1934] 2012) e "O artista como etnógrafo" ([1996] 2017) -, cotejando seus argumentos sobre o engajamento político do artista com as reflexões de Gayatri Spivak ([1985] 2010) sobre as preocupações do autor pós-colonial. Na segunda parte, analisamos as fotografias Desabamento do céu / Fim do mundo e Guerreiro de Tootobi conjuntamente à bibliografia acerca da série Sonhos, enfatizando o débito conceitual de Andujar com o xamanismo. Por fim, na terceira parte, propomos a noção de "autora-xamâ" a partir de três características do xamanismo no contexto amazônico: a função tradutora do xamã; o xamanismo como potência relacionada à visão e ao conhecimento ameríndios; e o caráter relacional da política e da influência do xamã. Dessa forma, pensamos a arte de Claudia Andujar como uma arte com os Yanomami - e não uma arte sobre os Yanomami.

Palavras-chave: Claudia Andujar; xamanismo; autor; Arte.

\begin{abstract}
:
The text proposes the formula "author as shaman" to affirm the presence of Amerindian shamanism in the elaboration of the photographic series Sonhos (2002-2004) by Claudia Andujar. For this, we divided the analysis into three moments. In the first part, we recover the texts of Walter Benjamin and Hal Foster about the figure of the author - "The author as producer" ([1934] 2012) and "The artist as ethnographer" ([1996] 2017) -, comparing their arguments about the artist's political engagement with Gayatri Spivak's reflections ([1985] 2010) on the post-colonial author's concerns. In the second part, we analyzed the photographs Crumbling of the sky / End of the world and Warrior of Tootobi with the bibliography about the series Sonhos, emphasizing the conceptual debt of Andujar with shamanism. Finally, in the third part, we propose the notion of "author-shaman" based on three characteristics of shamanism in the Amazon context: the translator function of the shaman; shamanism as a force related to Amerindian vision and knowledge; and the relational character of the shaman's policy and influence. Thus, we think of Claudia Andujar's art as an art with the Yanomami - and not an art about the Yanomami.
\end{abstract}

Keywords: Claudia Andujar; shamanism; author; Art.

\footnotetext{
${ }^{1}$ Mestrando em História no Programa de Pós-Graduação em História da Universidade Federal do Paraná (PPGHIS-UFPR). Bolsista CAPES. E-mail: garcez.joaop@gmail.com
} 


\section{Resumen}

El texto propone la fórmula "autora como chamán" para afirmar la presencia del chamanismo amerindio en la elaboración de la serie fotográfica Sonhos (2002-2004) de Claudia Andujar. Para ello, dividimos la argumentácion en tres momentos. En la primera parte recuperamos los textos de Walter Benjamin y Hal Foster acerca de la figura del autor - "El autor como productor" ([1934] 2012) y "El artista como etnógrafo" ([1996] 2017) -, comparando sus argumentos sobre el compromiso político del artista con las reflexiones de Gayatri Spivak ([1985] 2010) sobre las preocupaciones del autor poscolonial. En la segunda parte, analizamos las fotografías Desmoronamiento del cielo / Fin del mundo y Guerrero de Tootobi junto a la bibliografía sobre la serie Sonhos, destacando la deuda conceptual de Andujar con el chamanismo. Finalmente, en la tercera parte, proponemos la noción de "autor-chamán" desde tres características del chamanismo en el contexto amazónico: la función traductora del chamán; el chamanismo como una potencia relacionada con la visión y el conocimiento amerindios; y el carácter relacional de la política y la influencia del chamán. Por lo tanto, pensamos en el arte de Claudia Andujar como un arte con los Yanomami, y no como un arte sobre los Yanomami.

Palabras clave: Claudia Andujar; chamanismo; autor; Arte

"não há melhor ponto de partida para o pensamento que o riso."

(Walter Benjamin, O autor como produtor, p. 144)

Esse texto nasce de uma brincadeira. Ou seja, nasce da crença de que um jogo de palavras pode ter a potência de refletir um pensamento, de traduzir um tipo de saber. Da crença na potência da linguagem e da imaginação.

Ele nasce da leitura de uma série de autores e autoras que refletiram sobre a relação entre o(a) intelectual e/ou o(a) artista com a política. Que pensam, portanto, sobre o papel político do(a) intelectual e do(a) artista, se perguntando de que forma esses sujeitos, ocupantes de determinada posição de poder, podem se engajar com lutas minoritárias de diferentes atores políticos. Walter Benjamin, Gayatri Spivak, Hal Foster e Eduardo Viveiros de Castro, nossos interlocutores aqui, compartilham aproximações e distanciamentos em suas abordagens. Enquanto todos tentam refletir sobre uma certa horizontalidade na aliança entre o conhecimento ou a arte e os sujeitos minoritários da luta política - isto é, uma aliança onde a relação de poder entre eles não implique na tomada da palavra do Outro -, cada um pensa esse modelo de aliança de forma distinta, até por estarem lidando com diferentes referenciais de lutas e sujeitos políticos, fruto de suas distâncias espaciais e temporais, bem como de suas próprias formações teóricas e ideológicas. Um sinal desse dissenso - que entendemos positivamente - é expresso nos títulos dos textos de Benjamin e Foster: enquanto o primeiro nomeia seu texto que versa sobre essa aliança entre arte e política como $O$ autor como produtor ([1934] 2012), o segundo intitula O artista como etnógrafo ([1996] 2017). A primeira parte do título do nosso texto nasce daí: O autor como... xamã ! A partir dessa brincadeira com os textos de Benjamin e Foster podemos nos dedicar a pensar a mesma questão que ocupou esses autores - como pode um(a) artista/intelectual se engajar politicamente com o seu tempo? - a partir de outra figura, não mais o produtor (e o proletário de Benjamin) e o etnógrafo (e o sujeito pós-colonial de Foster), mas a figura do xamã. Isso implica considerar outros modelos de aliança e ampliar ainda mais a noção de "sujeito".

O segundo título do nosso texto continua essa linha de raciocínio. "O que deve a arte de Andujar aos Yanomami?”, ele pergunta. A própria formulação da questão dessa forma já indica um tipo de resposta em relação as questões anteriores; ou, melhor, indica um certo débito intelectual com a maneira pela qual 
Eduardo Viveiros de Castro (com algum eco de Spivak) respondeu a elas em sua "antropologia perspectiva". Se Viveiros de Castro pôde elaborar isso um pouco mais ao refletir sobre como as transformações na Antropologia advieram do pensamento de seus "objetos" de estudo - ou seja, de diferentes "sujeitos" e coletivos indígenas -, nós poderíamos levar a frente tais indagações desde outro "objeto" de estudo e em outro campo que não o da Antropologia. A série de fotografias Sonhos, de autoria de Claudia Andujar², nos oferece uma porta de entrada para esse experimento. Quando comenta a série, Andujar não hesita em destacar como tentou, nas fotografias, traduzir uma outra visualidade, que ela pôde conhecer na experiência do transe xamânico dos Yanomami. Assim, o que aconteceria se, seguindo a pista deixada por Andujar, nos esforçássemos em analisar suas fotografias desde a epistemologia xamânica e o pensamento ameríndio? Daí a pergunta-título: o que deve a arte de Andujar aos Yanomami? Acreditamos que, guiados por esse tipo de questão, compactuamos com a forma como Viveiros de Castro tenta empreender, em sua "reviravolta" epistêmica, um exercício de descolonização teórica, isto é, política.

Procedemos, então, com uma análise da série fotográfica Sonhos dentro do contexto maior da biografia de Claudia Andujar. A série apresenta uma gama de referências ao sonho e ao transe xamânico, tentando traduzir, de alguma forma, os seus tipos específicos de visualidade. Esse tipo de tradução que Andujar realiza em Sonhos será interpretado à luz do papel que a figura do xamã assume dentro do pensamento ameríndio, ou seja, de um "viajante de perspectivas". Levantamos a hipótese, portanto, que o devir-índio de Andujar responde as questões de Benjamin e Foster desde a rotação de perspectiva proposta por Viveiros de Castro a partir do pensamento ameríndio. Assim: A autora como xamán

\section{Figurações do autor}

“O autor como produtor" é o texto de uma conferência que Walter Benjamin realizou no Instituto para o Estudo do Fascismo de Paris em abril de 1934. Naquele momento de turbulência política, no qual o fascismo e o comunismo pareciam ser os principais vetores de atração da política europeia, Benjamin destaca que a arte e a poesia são confrontadas com a exigência de uma tomada política de posição, de assumir uma "tendência". Recusando que a assunção de uma tendência política "correta" implique em uma obra literária de "qualidade", Benjamin quer extrapolar, dialeticamente, a oposição entre forma e conteúdo, e, assim, teorizar sobre diferentes tipos de engajamento político que intelectuais e artistas, de seu presente, poderiam realizar. Para pensar sobre esses modos distintos de se engajar com as questões políticas de seu tempo, Benjamin traz alguns exemplos de artistas e/ou intelectuais. Dois desses exemplos, e que ganham

\footnotetext{
${ }^{2}$ Claudia Andujar (Neuchâtel/Suíça, 1931) é uma fotógrafa e ativista. Naturalizada brasileira, mora no país desde 1955, mesma época em que começou a fotografar - tornando-se, posteriormente, um nome importante na história da fotografia brasileira. Desde a década de 1970, envolve-se diretamente com os indígenas Yanomami, aliança que marcou tanto seu trabalho artístico quanto o ativista. Andujar se destacou por unir seu ativismo - com destaque para seu papel na Comissão de Criação do Parque Yanomami (CCPY), um dos centros mobilizadores da conquista da demarcação da Terra Indígena Yanomami, em 1992 - ao trabalho artístico, que carrega, assim, um forte caráter político - em sentido amplo, como argumentaremos aqui. Para uma visão geral da biografia e obra da autora, ver Boni (2010) e Soares (2011).

${ }^{3}$ Gostaria de remeter, desde já, ao trabalho da antropóloga Els Lagrou, que conheci somente em momento posterior a escrita desse texto, e que aborda em mais profundidade a relação entre arte e xamanismo, enfatizando, justamente, seu componente estético. Lagrou, inclusive, cunha a expressão "artista-xamã" para se referir a uma diferença entre o modelo do "artista ocidental" e do "artista indígena", onde o paradigma de imitação do mundo real é contrastado com a tentativa em elaborar uma ponte entre o mundo visível e o invisível. Além de se referir aos artistas indígenas e aos xamãs, o "artista-xamã" também se referiria à artistas "ocidentais" que assumem essa tarefa - Lagrou dá o exemplo dos surrealistas e, como sugerido nesse texto, também poderíamos pensar Claudia Andujar como tal. Ver Els Lagrou, Arte indígena no Brasil (2009) e Entre xamãs e artistas (2015).
} 
um bom destaque no texto, são os escritores Alfred Döblin (1878-1957) e Bertold Brecht (1898 - 1956). Döblin e Brecht aparecem como contrapontos na argumentação de Benjamin, como se cada um deles elaborasse um tipo de resposta à demanda de politização de suas artes.

Döblin funciona como um contraexemplo para Benjamin. Ele critica a concepção do "intelectual" de Döblin como "um tipo definido por suas opiniões, convicções e disposições, e não por sua posição no processo produtivo" (2012, p.136). Para Döblin, o lugar do intelectual na luta de classes é "ao lado" do proletariado, como um "protetor" ou "mecenas ideológico" do movimento. Benjamin se opõe incisivamente a tal posição; afirma não só que esse lugar, "ao lado" do proletário, é um "lugar impossível", como diz que "Döblin faz de tal socialismo uma arma contra a teoria e a práxis do movimento operário radical" (idem). Parece incomodar a Benjamin o caráter de logocracia ("reinado dos intelectuais") que o posicionamento de Döblin pressupõe (ibid., p. 135) - como se ele estivesse, na verdade, "acima" do proletariado.

Brecht, por outro lado, figura como exemplo do que Benjamin apresenta como postura desejada do "autor como produtor". Para ele, "Brecht foi o primeiro a confrontar o intelectual com a exigência fundamental: não abastecer o aparelho de produção, sem modifica-lo, na medida do possível, num sentido socialista" (ibid., p. 137). Dessa forma que o autor como produtor pode ser, de fato, "solidário com o proletariado" (ibid., p. 139). Assim, Benjamin pode afirmar que o autor consciente das condições de produção de sua época não aspiraria fabricar produtos, mas sim atuar sobre os meios de produção (ibid., p. 141). Era esse o conceito de "refuncionalização" de Brecht, que Benjamin admirava por sua "função organizadora”. Diferentemente da postura aristocrática de Döblin - se assim podemos dizer -, o exemplo de Brecht mostrava que a tendência [política], em si, não basta”, pois, "[...] a melhor tendência é falsa quando não prescreve a atitude que o escritor deve adotar para concretizá-la” (idem).

Em "O artista como etnógrafo", publicado em 1996 dentro do livro "O retorno do real", o crítico e historiador da arte Hal Foster procura retomar o texto de Benjamin para atualizá-lo. Por isso recupera o título do ensaio de Benjamin e torce os seus termos. Como os dois textos tem cerca de 60 anos que os separam, as preocupações políticas de Foster e dos artistas que analisa são outras em relação a Walter Benjamin. Assim, Foster pode propor a conformação de um novo paradigma na "arte de ponta da esquerda", estruturalmente semelhante ao do "autor como produtor", a saber, o "artista como etnógrafo". Esse paradigma, embora ainda conteste a "instituição de arte capitalista-burguesa", tem um novo "sujeito da associação", diferente do proletário com o qual se solidarizava Benjamin. Ele é o "outro cultural e/ou étnico". Para Foster, esse "desvio de um sujeito definido em termos de relação econômica para um sujeito definido em termos de identidade cultural é significativo", a ponto de sugerir, a partir dele, uma "virada etnográfica" na arte contemporânea (2017, p. 161-173). É necessário pensar essa mudança de termos proposta por Foster no bojo de algumas lutas políticas que animaram a segunda metade do século XX, principalmente a partir da década de 1960, como os movimentos sociais por direitos civis vinculados a categorias de raça e gênero, as lutas anticoloniais africanas, a contracultura, os processos de redemocratização na América Latina, entre outros tantos que conformavam esse quadro.

A virada etnográfica no campo da arte teria impulsionado, para Foster, uma nova inveja do etnógrafo por parte de artistas e críticos. Algumas características da Antropologia e do método etnográfico geravam essa irresistível atração: (1) o fato da Antropologia ser tomada como a ciência da alteridade; (2) ter a cultura como seu objeto de estudo - inflacionada no contexto de "pós-modernismo" de que fala Foster; (3) ser contextual - no que se concatenava com o discurso pós-colonial; (4) arbitrar o interdisciplinar; e (5) ter tido uma recente autocrítica de seus pressupostos (ibid., p. 170-171).

Foster levanta várias aporias para esse novo paradigma da arte de esquerda. De um lado, essa inveja em relação ao etnógrafo possibilitou a retomada de alguns motes que preocupavam Walter Benjamin: 
o etnógrafo, como figuração do autor, trabalha de modo horizontal com o sujeito da associação, atua em uma lógica espacial e material, e preocupa-se com a reflexividade sobre seu lugar de poder e enunciação. De outro lado, como na inteligência de esquerda analisada e criticada por Benjamin, os artistas como etnógrafos ainda corriam o risco de assumir uma espécie de "mecenato ideológico", agora expresso como "fantasia primitivista": isto é, o risco de reificar, na tentativa de aliança política, a essencialização do Outro como exterioridade do Eu - como fizera o movimento da négritude de Senghor e Césaire no contexto de descolonização africana, já precisamente problematizado por Kwame Appiah em seu "Na casa de meu pai: a África na filosofia da cultura" (1992).

A teórica literária Gayatri Spivak, em seu famoso "Pode o subalterno falar?” ([1985] 2010), alguns anos anterior ao de Foster, já havia se ocupado em pensar sobre tais aporias. Embora seu ensaio se dedique a considerar principalmente a figura do intelectual (e não do artista), a sua preocupação é similar à de Benjamin e Foster, e a questão da reflexividade sobre o lugar de poder e enunciação do intelectual (e do artista, por que não?) está no centro de sua reflexão, bem como o perigo de reificação de uma diferença estática - o que Foster chamou de "fantasia primitivista", e que Spivak chama de "violência epistêmica" (2010, p. 60). Spivak faz questão de, ao longo do texto, refletir sobre seu próprio lugar de fala, pois, se o fato de ser uma mulher indiana lhe coloca dois marcadores de subalternidade, ela entende que, ao se tornar uma intelectual, já está ocupando postos de poder - o que revela, de maneira clara, o caráter relacional da subalternidade. O subalterno, para a autora, é aquele(a) que tem a fala impedida de reconhecimento e consequente escuta. É uma posição, e não condição social - o que significa dizer: é algo situacional, contingencial, relacional, e não essencial. Assim, a preocupação maior de Spivak é saber não se o subalterno pode falar, pois é óbvio que sim, mas como pode o subalterno ser ouvido?

Desde essa questão, e de acordo com Benjamin e Foster, Spivak analisa algumas posturas de intelectuais do assim chamado pós-estruturalismo, utilizando-os como exemplos para sua argumentação. $\mathrm{O}$ ponto de partida é o conhecido diálogo entre Michel Foucault e Gilles Deleuze, publicado sob o título de "Os intelectuais e o poder" (1979). A forma como os autores pensam o engajamento político do intelectual, nessa conversa, poderia ser resumida na figura do intelectual que se ausenta para dar voz aos subalternos. Deleuze falava - no contexto do Grupo de Informação sobre as Prisões, criado pelo próprio Foucault - em "estabelecer condições nas quais os prisioneiros seriam capazes de falar por si mesmos" (1979, p. 70), enquanto que Foucault afirmava que "as massas sabem perfeitamente bem, claramente [...] eles sabem muito mais que [o intelectual] e certamente o dizem muito bem" (ibid., p. 71). Spivak faz algumas ponderações a tais formulações, pois acredita que ambos deslizam ao tratar de "sujeitos em revolução monolíticos e anônimos" - seja o "maoísta" de Foucault ou os "trabalhadores" de Deleuze -, ao ignorar a divisão internacional do trabalho, e ao separar a esfera do poder à do desejo - como se o desejo não fosse ideologicamente informado. Assim, Spivak afirma que Deleuze e Foucault, ao supor uma ausência do intelectual, acabam fundando um sujeito soberano do conhecimento, que não reflete, justamente, sobre seu lugar social e sua posição de poder.

Em contraposição a tal posicionamento, Spivak enfatiza a responsabilidade institucional do crítico, e defende que o intelectual deveria assumir a tarefa de uma "produção ideológica contra-hegemônica" (2010, p. 160). Essa figura do intelectual não se "ausenta" da fala, mas assume, justamente, seu lugar privilegiado de enunciação. E, também, reconhece a heterogeneidade dos sujeitos subalternos, recusando, portanto, a reificar a essencialização deles através de outro tipo de valoração - em vez da negativa, que afirmava que negros, pobres ou mulheres são sujeitos intrinsicamente inferiores, uma valoração positiva, que afirmaria que todo negro é antirracista, que todo pobre é anticapitalista, ou que todas mulheres seriam feministas; uma posição um tanto longe da realidade, e que, em sua benevolência, acaba por consolidar uma diferença essencial do Outro. Para dar esse passo, Spivak traz o exemplo da filosofia da diferença elaborada 
por Jacques Derrida em Gramatologia. Derrida estava preocupado em impedir que esse sujeito etnocêntrico do conhecimento estabelecesse a si (o Eu) através da definição de um Outro, e assim que colocava sua crítica ao "pensamento logocêntrico europeu". Sua proposta não era deixar que o outro fale por si mesmo, mas um apelo ao "quase-outro", ou seja, um chamado a possibilidade de "tornar delirante aquela voz interior que é a voz do outro em nós" (DERRIDA apud SPIVAK, 2010, p. 165). Assim, com Spivak, retomamos o mote da preocupação de Benjamin e Foster, sem deixar de considerar as aporias que Foster levantou para esse artista/ intelectual que está em aliança com o sujeito identitário das lutas políticas contemporâneas.

Com tal problemática em mente, podemos nos deter ao nosso estudo de caso em particular, refletindo, nos termos colocados, sobre a figuração do autor que emerge do trabalho de Claudia Andujar. Assim, Andujar pode ser um outro exemplo de artista/intelectual que enfrenta as aporias do engajamento político, e que não só assume essa tarefa, como elabora uma maneira "xamânica" de lidar com ela.

\section{A série Sonhos e as fotografias xamânicas de Claudia Andujar}

Espectros indígenas dançam sob o rio. A fotografia parece sobrepor a execução de um ritual dentro da maloca - como as estruturas apagadas no lado direito da foto supõem - com um rio que cai até ela e lhe ilumina. O rio e a luz atravessam o rito e aqueles corpos, e toda materialidade da cena se dilui nágua. Os corpos banham e dançam no rio. Não só extrapolam a fronteira humano-natureza, como lembram que o corpo também é água. E se é o céu que desaba na fotografia, também ele é feito de água. A fotografia, expo-

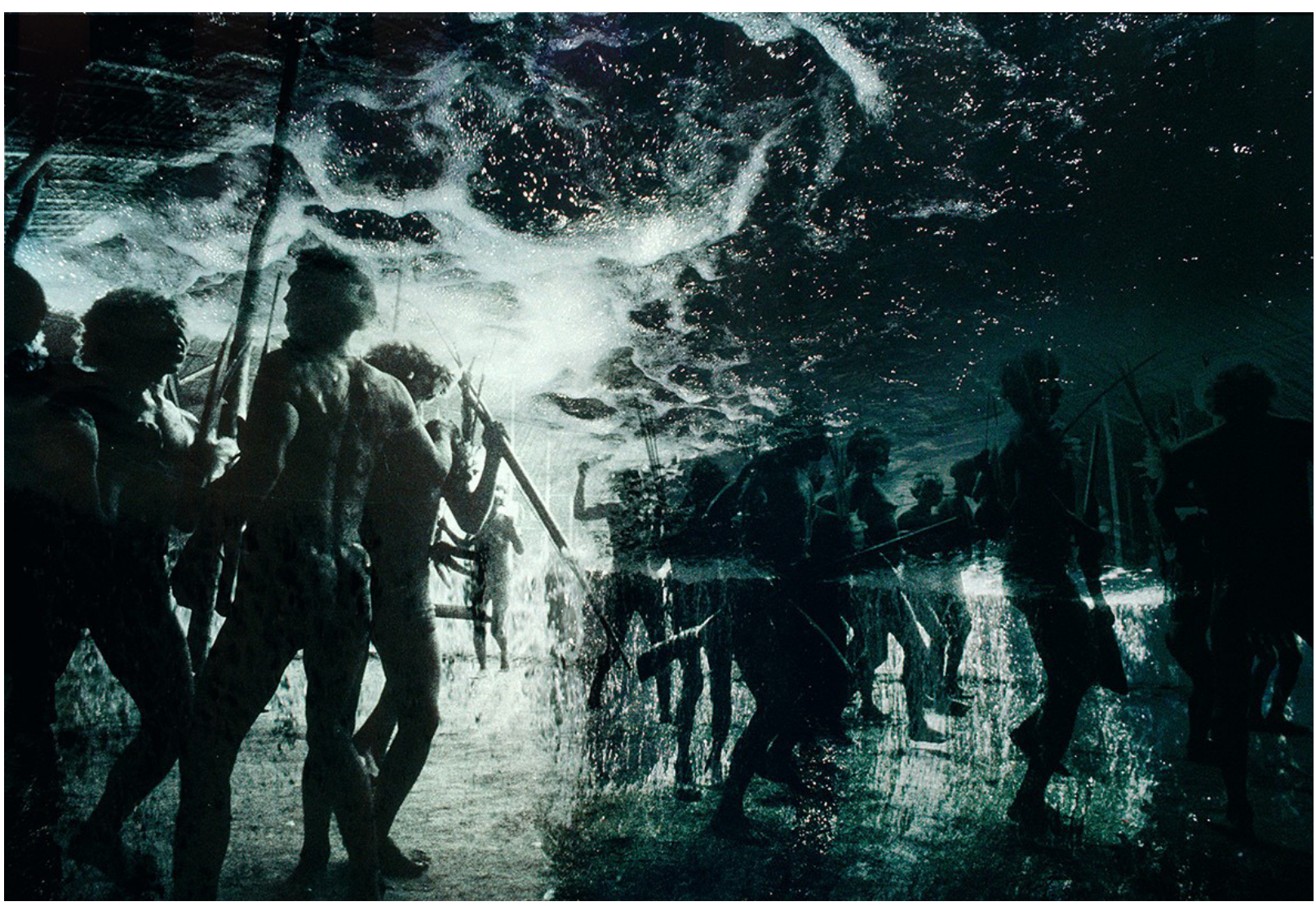

Figura 1 - Desabamento do Céu / Fim do Mundo. Fonte: Galeria Vermelho4, 1976.

\footnotetext{
${ }^{4}$ Agradeço a Galeria Vermelho, que representa Claudia Andujar, pela cessão dos direitos de usos das fotografias e de seus arquivos digitais.
} 
sição de luz, carrega múltiplos sentidos: não só o registro de um ritual yanomami, o destaque para o lugar do rio e da natureza nas filosofias ameríndias, ou o uso da técnica espectral de sobreposição de imagens... ela também é uma tentativa de expressar visualmente a experiência do transe xamânico, uma proposta de se deixar afetar por ela, de transportar sua potência e expandir visualidades.

Desabamento do céu / Fim do Mundo é uma fotografia de Claudia Andujar, fotógrafa e ativista suíço-brasileira que atua desde os anos 1970 na defesa dos direitos e da vida dos povos indígenas. O nome de Andujar se confunde com os Yanomami, povo com o qual Andujar conviveu por cinco anos (entre 1972 e 1976), após ter se encantado com sua cultura, e construiu um farto acervo fotográfico - do registro da violência de Estado da série Marcados ([1981-1984] 2009) às experiências oníricas de Sonhos ([1974-2003] 2005) - que até hoje é decantado no intuito de atentar para essas vidas. Se Andujar chegou até os Yanomami com o objetivo inicial de "conhecer o povo brasileiro"116, é no final da década de 1970, ao perceber os efeitos catastróficos que os projetos desenvolvimentistas do regime militar causavam na Amazônia e sofrer constrangimentos para deixar a mata, que a fotógrafa passa a atuar como ativista pública em defesa das vidas yanomami, ao mesmo tempo em que trazia à tona, através do campo artístico, a violência estatal brasileira com os povos indígenas e o meio ambiente (BONI, 2010, p. 259-261). Além de sua atuação no campo da arte - através de exposições, fotolivros ou fotofilmes -, Andujar também fundou em 1978, com Carlo Zacquini, Bruce Albert e Alcida Ramos, entre outros, a ONG Comissão pela Criação do Parque Yanomami (CCPY), voltada a preservar os direitos territoriais, civis e culturais dos Yanomami, e que atuou, até os anos 2000, em diversas frentes de aliança com os indígenas, colaborando, inclusive, com a conquista da demarcação da Terra Indígena Yanomami, homologada em 1992.

Sobre seu trabalho fotográfico, Carolina Soares (2011) e Vera Lúcia Pereira (2016), pesquisadoras da obra de Andujar, argumentaram, em suas respectivas tese e dissertação, que as fotografias da artista saem do âmbito de um registro documental do real - um verdadeiro carma que a inovação técnica da fotografia carregou em boa parte de seus debates teóricos - e são melhor compreendidas no escopo da expressão poética. Sandra Gonçalves, por sua vez, ao se deter especificamente na série de fotografias Sonhos, na qual a Desabamento do céu / Fim do Mundo está inserida, afirma que essa "fotografia expandida" de Andujar dá-se por "meio de fotomontagens, feitas a partir de transparências de fotografas coloridas e em preto e branco, oriundas de seu arquivo, [nas quais] Andujar realiza sobreposições e hibridações, criando novas imagens, próximas a abstração" (2016, p. 158). Para Gonçalves, Andujar usa esse recurso justamente para dar conta do que está além do "real": o invisível, o espiritual e a relação entre os indígenas e a floresta, seus rituais e mitologia (ibid., p. 159).

A fotografia Desabamento do céu / Fim do Mundo é um exemplar do uso de sobreposições dentro da obra de Claudia Andujar. Em sua entrevista para Ana Maria Mauad (2012), Andujar afirma que mobiliza essa técnica e a "tecnologia ocidental" como um meio para "entrar no universo" Yanomami. Ela diz que as referências para essa estética de sobreposições fotográficas não vieram do trabalho de outros artistas; é uma estética que emerge desde o estado de transe xamânico, dos sonhos e das viagens dos xamãs quando realizam sua diplomacia intra e extraespecífica. Não é à toa que Davi Kopenawa, um xamã Yanomami, pode dizer que sabe o que se passa na fotografia, e que sabe mais e melhor do que a própria fotógrafa - como relata Andujar:

O trabalho cresceu conforme eu conheci melhor os Yanomami e a espiritualidade deles. É isso que eu posso dizer. Por exemplo, a série de superposições nasceram por causa disso. Não é que eu vi outras superposições no trabalho de outras pessoas. As superposições que eu chamo de sonhos, são os sonhos dos xamãs. Eles chamam isso de sonhos, de viagens. Eles dão esse nome para isso, não as minhas fotos, o estado de ser deles. Isso acontece quando eles entram em contato com os espíritos. [...] Eu sempre faço questão de colocar a questão da luminosidade, porque faz parte das crenças deles [...] Eu diria, eu uso a tecnologia nossa, ocidental, isso sim. Mas 
tentando manipular as coisas com o que eu conheço da tecnologia ocidental. Mas entrando no universo deles. [...] Mas, o que me dá uma certa satisfação é que quando eu mostro esse trabalho aos Yanomami eles percebem isso. Eles fazem o que faziam com os desenhos, ele vê essa imagem com toda essa invasão de luz e ele começa a contar a sua história. Um dia eu tinha esse trabalho Sonhos na Galeria vermelho exposto e o Davi [Kopenawa] estava lá, estava em São Paulo e eu levei ele lá. Ele começou a falar, explicar o que eram aquelas fotos para mim, para quem estava lá. Eu estava lá, tinha umas pessoas da galeria e ele falou: "agora eu vou explicar para vocês o que vocês estão vendo". As pessoas ficaram com a boca aberta: "mas como? Quem tem que explicar isso é a Cláudia, como que você sabe". "Ah, porque eu sei, eu sei mais do que ela". Ele não falou isso. Mas ele falou: "Eu sei o que é isso". Claro, não tenho dúvida, eu não sei tudo. De jeito nenhum. Eu tentei enxergar o que eu entendi. (ANDUJAR apud MAUAD, 2012, p. 139, grifos nossos)

É essa tentativa de expressar visualmente, através da fotografia, a experiência do transe, as viagens-sonhos xamânicas e o mundo da cosmologia yanomami, que animaram a elaboração da série Sonhos por parte de Andujar. A série foi idealizada para participar da exposição Yanomami, lesprit de la forêt, que ficou em cartaz na Fundação Cartier em Paris, entre maio e outubro de 2003, a convite do curador Hervé Chandes (MORAES, 2018, p. 2), e foi composta a partir do arquivo de imagens que Andujar havia construído na Amazônia. A série também foi publicada, em 2005, dentro do fotolivro A vulnerabilidade do ser, editado pela Cosac Naify. Todas as vinte fotografias que fazem parte da série utilizam a técnica da sobreposição de imagens. Essas imagens espectrais que resultam das sobreposições, criam uma espécie de comunhão entre os corpos fotografados - sejam de indígenas ou de animais - e a natureza, reverberando certos aspectos da ontologia presente no pensamento ameríndio.

Alberto Luiz de Andrade Neto (2018) e Ana Carolina Albuquerque de Moraes (2018) se dedicaram a pensar a série nessa relação com o pensamento ameríndio. Enquanto Neto tentou compreender o xamanismo amazônico colocando em diálogo a série Sonhos com o monumental A queda do céu (2015) - obra-manifesto fruto do pacto etnográfico entre o antropólogo Bruce Albert e o xamã Davi Kopenawa -, Moraes quis trazer à tona, a partir de Sonhos e do fotofilme Povo da Lua, Povo de Sangue (1985) - coautoria de Andujar e Marcello Tessara - alguns aspectos do transe yanomami. Destacando como o brilho e o sonho são reinvindicados, na fala de Kopenawa, como experiências de acesso ao estado em que os xamãs podem ver os xapiri (espíritos da floresta) e seu mundo sobrenatural, Neto observa que o uso de brilho e de fortes contrastes nas fotografias oníricas de Andujar querem "dar a ver" esses aspectos do xamanismo yanomami: "os clarões, a cintilação e a resplandecência de suas fotografias são lampejos de uma reflexão grandemente apoiada na própria ontologia dos espíritos amazônicos que tendem a uma poética indígena de muito brilho" (2018, p. 19).

Na fotografia Guerreiro de Tootobi, vemos a cena de um indígena curvado - ou seria um xapiri? -, segurando algum instrumento na mão, que, em seu movimento, ativa ondas de luz, ao mesmo tempo em que se torna indiscernível no contraste com a luminosidade ofuscante delas. Também notamos que ele está sob algum tipo de estrutura, e lá atrás, na cena, ocorre uma dança, talvez dentro de algum rito yanomami. Mas o que chama a atenção mesmo é a luz ofuscante, o contraste, o azul, e a diferença do protagonista. Somos levados, com eles, à busca de significantes para a imagem que estão em outro regime de visualidade, em outro cosmos. Pode ser um convite ao experimento da "renúncia ao estado de vigília, [...] a perda de consciência que permite ao indivíduo ingressar em estado de sonho, no qual surgem visões atribuídas a um mundo sobrenatural", que foi a forma como Moraes definiu a maneira como o uso da yãkoana ${ }^{5}$ impactaria a visualidade dos xamãs na experiência do transe (MORAES, 2018, p. 3).

\footnotetext{
${ }^{5}$ A yãkoana é o pó fabricado a partir da resina presente na parte interna da casca da árvore Virola elongata, que contém um poderoso alcaloide alucinógeno, a dimetriltriptamina (DMT), e é misturado com algumas folhas secas e cinzas de cascas de árvores. Ver Davi Kopenawa \& Bruce Albert, A queda do céu, 2015, p. 612, nota 15.
} 


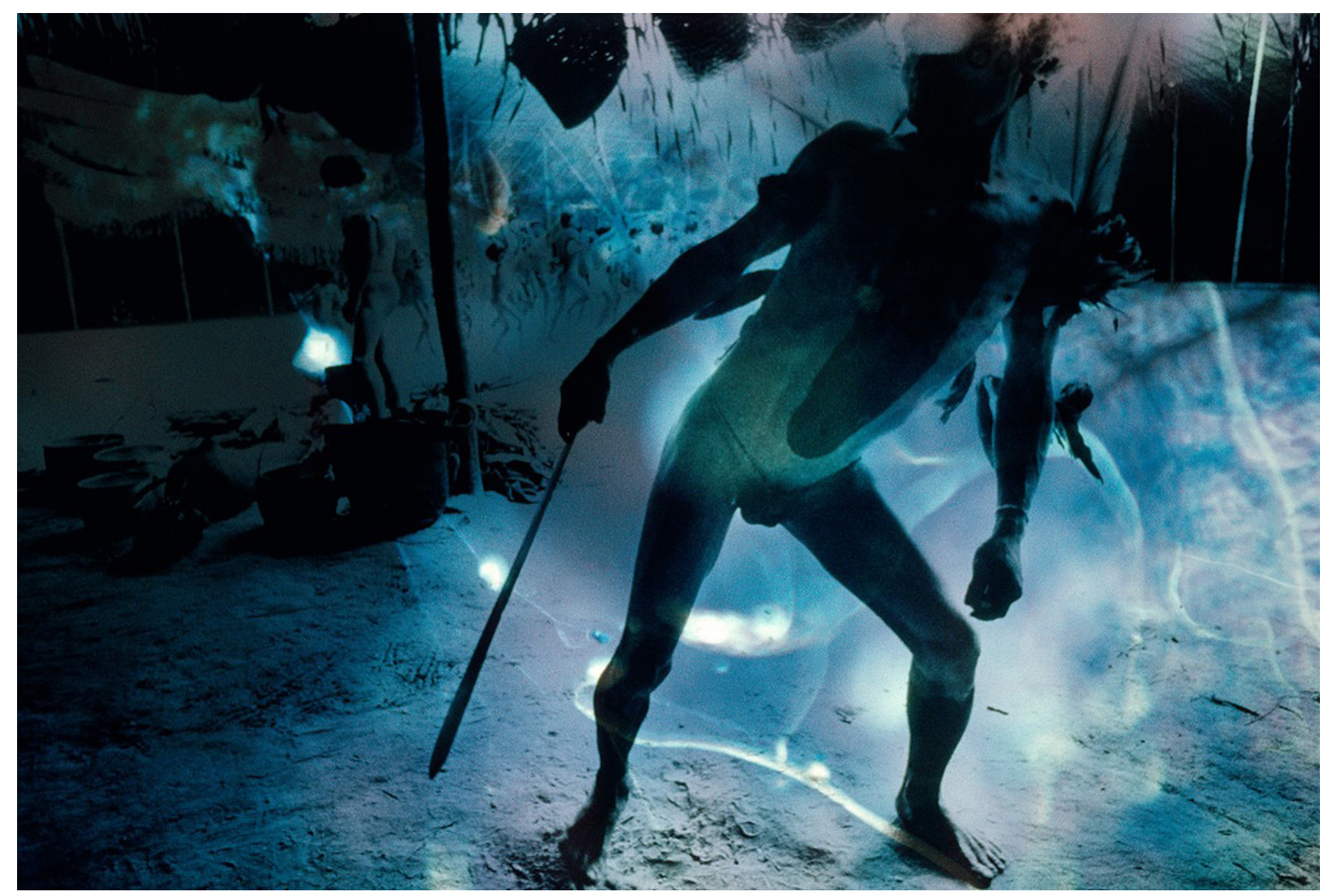

Figura 2 - Guerreiro de Tootobi. Fonte: Galeria Vermelho, 1976.

Essa intersecção entre xamanismo amazônico e pensamento ameríndio com as fotografias de Sonhos, que propõem Moraes e Neto, é muito interessante para pensarmos dois tipos de ruptura na obra de Andujar. Em primeiro lugar, reitera aquela conclusão de Soares e Pereira que afirmava que as fotografias de Andujar estão além da dimensão do documental. Essa expressão poética do invisível, por parte de Andujar, também marcaria, irreversivelmente, sua passagem do campo do fotojornalismo para o das artes visuais. Em segundo lugar, a ruptura com os modelos de representação do indígena no repertório iconográfico brasileiro desde o século XIX, a saber, o modelo integracionista e o modelo romântico (DE TACCA, 2011; SOARES, 2011). Carolina Soares e Fernando de Tacca, ao afirmarem a particularidade de Andujar nessa história, destacavam uma certa dinâmica etnográfica do trabalho da fotógrafa, ou seja, tanto o caráter contingencial de sua obra, como a cumplicidade com os sujeitos fotografados. Penso que a série Sonhos, e as análises de Moraes e Neto, avançam alguns passos nesse sentido. Fazem pensar, justamente, sobre o tipo de engajamento da artista, e em como ela concebeu o papel político da sua obra. Não é à toa que Neto diz que as fotografias de Andujar são fruto de um "pacto" e de uma "negociação conceitual" entre a artista e seus anfitriões, e que é destas experiências de colaboração que emergem a sua produção fotográfica (2018, p. 20); enquanto que Moraes coloca que Andujar se recusa a "sobrepor sua própria visão de mundo àquela do povo representado", e tenta "atuar como uma espécie de mediadora que transforma em imagens aquilo que espontaneamente lhe chega do outro" (2018, p. 3, grifo nosso).

Claudia Andujar soube, de maneira ímpar, apresentar a vastidão desse "mundo" Yanomami - uma apresentação refinada, engajada, negociada e com os louros merecidos. E isto só ocorreu quando o corpo de Andujar - seja este corpo técnico, político, epistemológico e físico - também foi transformado neste confronto com uma nova ontologia. (NETO, 2018, p. 17) 


\section{A autora como xamã}

Voltamos, portanto, à questão-motor do ensaio, a saber: os tipos de engajamento político e as figurações do autor daí advindas. Quero sugerir, em conformidade com a análise da série Sonhos, que mais do que a figura do produtor ou do etnógrafo, o que emerge do engajamento de Claudia Andujar com os Yanomami é outra figura: a do autor-xamã. Essa figuração, além de colocar a fotógrafa dentro do nosso debate principal, pode ser uma forma de condensar as rupturas de sua obra - biográfica, em relação ao documental e ao fotojornalismo, e histórica, em relação aos modos iconográficos de representação do indígena. Para proceder com essa conceituação, gostaria de chamar atenção para três características do xamanismo no contexto amazônico: (1) a função tradutora do xamã; (2) o xamã como potência relacionada à visão e ao conhecimento; e (3) o caráter relacional da política e da influência do xamã.

A função tradutora do xamã. Em Pontos de vista sobre a floresta amazônica: xamanismo e tradução (1998), Manuela Carneiro da Cunha oferece elementos para pensarmos essa correlação entre a mediação de Andujar com a tradutibilidade empregada pelos xamãs. Nesse texto, a partir da literatura etnográfica sobre a região, Cunha se pergunta: o que é o trabalho xamânico na Amazônia de hoje? Como entender o xamanismo em condições de dominação colonial? A antropóloga quer entender, assim, por exemplo, como Crispim, um xamã do Alto Juruá, mesmo tendo sido criado e estudado entre os brancos, pôde, ao voltar para os seus, assumir uma elevada reputação xamânica - segunda a autora, Crispim foi por décadas, até sua morte no início dos anos 1980, o mais respeitado xamã do Alto Juruá, seja por parte dos indígenas ou dos seringueiros. Para o próprio Crispim, sua reputação xamânica se explicava por ter morado e estudado em dois lugares significativamente diferentes. Na sua explicação, há um esboço da "função" do xamã, e de como essa figura pode ser entendida, no contexto do universo amazônico, como a do "viajante por excelência" (CUNHA, 1998, p. 12). Segundo Cunha, cabe ao xamã "interpretar o inusitado, conferir ao inédito um lugar inteligível, uma inserção na ordem das coisas" (idem). Por isso, sua tarefa se aproximaria a do tradutor. Mas não aquele tradutor que faz a ordenação de coisas novas em "velhas gavetas", o xamã amazônico é aquele que reúne em si mais do que um ponto de vista, que assume uma linguagem parcial, e que afirma, portanto, a "verdade da relatividade" (na conhecida fórmula de Deleuze, apud CUNHA, 1988, p. 13); pois é de sua função colocar-se em perspectiva, ver a partir de outros modos e outros mundos, e daí tentar reconstruir sentidos, estabelecer relações, encontrar intimas ligações (ibid., p. 13-17). É o xamã, nesse contexto, que assume a tarefa diplomática de "totalização de pontos de vista singulares e irredutíveis" (ibid., p. 17).

O xamã como potência relacionada à visão e ao conhecimento. Sobre o mesmo contexto de Cunha, Eduardo Viveiros de Castro afirmava que "o xamanismo é essencialmente uma diplomacia cósmica dedicada à tradução entre pontos de vista ontologicamente heterogêneos" (2006, p. 320). Essa diplomacia cósmica não é um atributo substantivo, mas uma "qualidade ou capacidade adjetiva ou relacional", uma "qualidade que pode estar intensamente presente em muitas entidades não-humanas, que abunda, escusado dizer, nos 'espíritos', e que pode mesmo constituir-se em potencial genérico do ser" (ibid., p. 322). Ou seja, o xamã não é um sujeito imbuído de uma capacidade transcendental, essencial, de tradutor cósmico; "ser xamã" se refere à capacidade de ser outra coisa, à potência de ver (e ser visto) de outra forma, de viajar entre pontos de vista. $\mathrm{O}$ xamanismo tem a ver, portanto, com a visualidade como modelo de percepção e conhecimento nas culturas ameríndias. Não é à toa que o aprendizado para se tornar xamã ocorre a partir do acontecimento de ver e ser visto pelos espíritos xapiri. Viveiros de Castro, inclusive, afirma que xapiri se refere a uma condição um pouco mais heterogênea do que a tradução espírito parece impor: os xapiri seriam formas espectrais ou imagens, pois o termo não se refere ao que são, mas a como humanos, não-humanos e animais podem se apresentar. As imagens-xapiri seriam, então, o "signo do fundo uni- 
versal imanente - o fundo que vem à tona no xamanismo, no sonho e na alucinação, quando o humano e o não-humano, o visível e o invisível trocam de lugar" (ibid., p. 326). Por isso o recurso a yãkoana - e o transe - e ao sonho como "próteses visuais" ou "instrumentos de tecnologia xamânica", pois eles auxiliam na "desterritorialização do olhar", isto é, na busca da "experiência perceptiva da intensidade luminosa", que possui um valor conceitual em si mesma (ibid., p. 330-332) - também não é à toa a busca por intensidades luminosas nas fotografias xamânicas de Andujar, como observamos.

O caráter relacional da política e influência do xamã. Se já podemos assumir que o xamã, na sua diplomacia e tradução de diversos pontos de vista heterogêneos, tem um papel político e de liderança, precisaríamos entender como isso se dá em um contexto amazônico de "política da consideração". Esse termo foi cunhado por José Antonio Kelly e Marcos de Almeida Matos (2019), a partir de uma vasta série de exemplos etnográficos da Amazônia, para pensar como as formas de organização e ação dos coletivos indígenas dessa região envolvem uma "interdependência de pessoas que alternam as respectivas posições enquanto 'causa dos atos de outrem' e 'agente que tem outrem em mente"' (KELLY; MATOS, 2019, p. 392). No caso do xamanismo yanomami, essa condição relacional - interdependente - do xamã é expressa no fato de que "ser visto pelas imagens-espírito é uma precondição para a aquisição da habilidade de ver o mundo das imagens-espírito como esses espíritos o veem" (ibid., p. 397). Ou seja, o xamã só atua como tal quando é causa da consideração dos xapiri e, assim, pode vir a ser agente que os vê e os considera - a própria yãkoana, nesse contexto, é inalada pelos xamãs como alimento para os xapiri: uma ação de consideração para outrem (ibid., p. 410). Assim, a política do xamã precisa ser entendida nesse contexto geral de "política da consideração". Pois ele, em momento algum, se vê acima de algo ou alguém (para recuperar a imagem de Benjamin sobre Döblin), mas está sempre em constante afetação, sendo causa e agente ao mesmo tempo. Não é bem um líder, mas exerce influência - Kelly e Matos usam "influência" como um entre-lugar dos tipos coercitivo e não-coercitivo de poder (para lembrar os conceitos de Pierre Clastres), como se ela se referisse a um "fazer fazer" ou "fazer agir"; isto é, um tipo de performance que pressupõe que a eficácia (ou não) de uma ação está sendo sempre atestada (considerada) por outrem.

Não seria precipitado dizer que Andujar assumiu a posição de xamã? Ou dizer que um autor poderia fazer tal coisa? Talvez sim. Mas cabe lembrar que aqui sempre tratamos de exemplos, e não de modelos. "O modelo dá ordens, o exemplo oferece pistas", já disse certa vez Viveiros de Castro (2017). O xamã, portanto, como exemplo, ou seja, como alguém (uma posição) que oferece pistas para a atuação do intelectual e/ou artista preocupado em se engajar politicamente com as lutas de seu tempo. Andujar ou um qualquer autor não precisam ser xamã, de fato, para seguirem essas pistas.

O exemplo do autor-xamã, como vimos, pode dialogar com uma certa literatura que se ocupou com tal preocupação política. A necessidade de um engajamento material e horizontal do autor-produtor de Walter Benjamin; a preocupação com outros sujeitos minoritários e o cuidado com a "fantasia primitivista" do autor-etnógrafo de Hal Foster; o destaque a heterogeneidade e o chamado a ouvir o "quase-outro" que habita em nós de Gayatri Spivak; são elementos que aparecem, em outros termos, dentro do trabalho "xamânico" de Claudia Andujar. Assim, Andujar construiu um modo relacional e horizontal de se envolver com os Yanomami - uma aliança que precisa ser lida dentro da lógica de uma "política da consideração"; se preocupou em levar a sério o tipo de conhecimento e visualidade que o xamanismo yanomami assume - não colocando, portanto, essa experiências como um "folclore" ou um tipo de saber "primitivo"; e assumiu o lugar de uma viajante de perspectivas que tentou traduzir essa 
experiência de habitar mais do que um mundo, de ser o "quase-outro" - sem pressupor, para isso, uma hierarquia entre as duas "línguas" da tradução".

Para finalizar, gostaria de dedicar breves palavras à tradução visual de Andujar. "O que deve a arte de Andujar aos Yanomami?” era o que nos perguntávamos acima. Se, conforme fez Viveiros de Castro em sua antropologia perspectiva, já assumimos que a tradução também era o mote principal da série Sonhos de Andujar, somos levados a algumas conclusões análogas. A antropologia, naquela formulação, não era bem um conhecimento sobre os povos nativos, mas sim um conhecimento com eles - um tipo de conhecimento simétrico. De certo modo, como quisemos chamar atenção aqui, a arte de Andujar não é uma arte sobre os Yanomami, mas uma arte com os Yanomami, uma arte quase-Yanomami: um exercício de perspectivismo, uma antropofagia, um canibalismo conceitual-visual. Talvez, assim, a arte de Andujar compartilhe daquela "verdadeira missão" da antropologia perspectiva: "ser a teoria-prática da descolonização permanente do pensamento" (VIVEIROS DE CASTRO, 2015, p. 20) e, por que não?, de descolonização dos regimes de visibilidade.

\section{Referências}

ANDUJAR, Claudia. Sonhos. In: A vulnerabilidade do ser. São Paulo: Cosac Naify, 2005. Marcados. São Paulo: Cosac Naify, 2009.

APPIAH, Kwame Anthony. Na casa de meu pai: a África na filosofia da cultura. Rio de Janeiro: Contraponto, 1997.

BENJAMIN, Walter. Magia e técnica, arte e política: ensaios sobre literatura e história da cultura. Vol.1. São Paulo: Brasiliense, 2012.

BONI, Paulo Cesar. De passado turbulento a ativista com causa. Discursos Fotográficos, v. 6, n. 9, p. 249-273, 2010.

CÉSAIRE, Aimé. Discurso sobre o colonialismo. Tradução Anísio Garcez Homem. Florianópolis: Letras Contemporâneas, 2017.

CLASTRES, Pierre. A sociedade contra o Estado - pesquisas de antropologia política. Sâo Paulo: Cosac Naify, 2013.

CORNELSEN, Elcio. Considerações sobre o "O autor como produtor". Revista Literatura e Autoritarismo. n. 5. Dossiê Walter Benjamin e a literatura brasileira. São Paulo, 2010.

CUNHA, Manuela Carneiro da. Pontos de vista sobre a floresta amazônica: xamanismo e tradução. Mana, v. 4, n. 1, p. 7-22, 1998.

DELEUZE, Gilles; FOUCAULT, Michel. Os intelectuais e o poder. In: FOUCAULT, Michel. Microfísica do poder. Rio de Janeiro: Graal, 1979.

DE TACCA, Fernando. O índio na fotografia brasileira: incursões sobre a imagem e o meio. História, Ciências, Saúde-Manguinhos, v. 18, n. 1, p. 191-223, 2011.

\footnotetext{
${ }^{6}$ Cabe lembrar como Viveiros de Castro coloca o trabalho de tradução da antropologia como um tipo de traição: "E se traduzir é sempre trair, conforme o dito italiano, uma tradução digna deste nome - aqui estou parafraseando (traduzindo) Walter Benjamin, ou antes, Rudolf Pannwitz - é aquela que trai a língua de destino, não a língua do original. A boa tradução é aquela que consegue fazer com que os conceitos alheios deformem e subvertam o dispositivo conceitual do tradutor, para que a intentio do dispositivo original possa ali se exprimir, e assim transformar a língua de destino. Tradução, traição, transformação." Ver Eduardo Viveiros de Castro, Metafísicas canibais, 2015, p. 87.
} 
FOSTER, Hal. O artista como etnógrafo. In: O retorno do real: a vanguarda no final do século XX. Tradução Célia Euvaldo. São Paulo: Ubu Editora, 2017.

GONÇALVES, Sandra Maria Lúcia Pereira. A alma da floresta: Sonhos, por Claudia Andujar. Revista Gama, Estudos Artísticos, 4(7), p. 152-160, 2016.

KELLY, José Antonio; MATOS, Marcos de Almeida. Política da consideração: ação e influência nas terras baixas da América do Sul. Mana, v. 25, p. 391-426, 2019.

KOPENAWA, Davi; ALBERT, Bruce. A queda do céu: palavras de um xamã yanomami. São Paulo: Companhia das Letras, 2015.

LAGROU, Els. Arte indígena no Brasil: agência, alteridade e relação. Belo Horizonte: C/Arte, 2009.

Entre xamãs e artistas: entrevista com Els Lagrou. Revista Usina, n. 20, 2015.

LINO, Tayane Rogeria. O lócus enunciativo do sujeito subalterno: fala e emudecimento. Anuário de literatura: Publicação do Curso de Pós-Graduação em Letras, Literatura Brasileira e Teoria Literária, v. 20, n. 1, p. 74-95, 2015.

MAUAD, Ana Maria. Imagens possíveis: Fotografia e memória em Claudia Andujar. Revista Eco-Pós, v. 15, n. 1, p. 124-146, 2012.

MORAES, Ana Carolina Albuquerque de. Claudia Andujar e Marcelo Tessara: o transe yanomami na fotografia e no cinema. Artelogie, 12 | 2018.

NETO, Alberto Luiz de Andrade. Brilhos e sonhos: caminhando com Andujar, Kopenawa e Albert. REIA Revista de Estudos e Investigações Antropológicas, ano 5, vol. 5 (1), 2018.

PEREIRA, Vera Lúcia. Marcados, de Claudia Andujar: do documento visual à imagem poética. Dissertação. Universidade Federal de Uberlândia, Programa de Pós-Graduação em Artes. 2016.

SPIVAK, Gayatri Chakravorty. Pode o subalterno falar? Belo Horizonte: Editora UFMG, 2010.

SOARES, Carolina Coelho. Uma bricolagem virtual infinita: a representação do indígena no trabalho de Claudia Andujar (1960/70). 2011. Tese de Doutorado. Universidade de São Paulo.

VIVEIROS DE CASTRO, Eduardo. A inconstância da alma selvagem e outros ensaios de antropologia. São Paulo: Cosac Naify, 2002.

A floresta de cristal: notas sobre a ontologia dos espíritos amazônicos. Cadernos de Campo, v. 15, n. 14-15, p. 319-338, 2006.

Metafísicas canibais: elementos para uma antropologia pós-estrutural. São Paulo: Cosac Naify, 2015.

O modelo e o exemplo: dois modos de mudar o mundo. Conferência Ministrada na Universidade Federal de Minas Gerais em 9 de outubro de 2017. Disponível em: https://www.youtube.com/watch?v= PfE54pj1wU. Acesso em 19 de janeiro de 2020.

. A antropologia perspectiva e o método de equivocação controlada. ACENO-Revista de Antropologia do Centro-Oeste, v. 5, n. 10, p. 247-264, 2019.

Recebido em 28/10/2020

Aceito em 23/11/2020 
